\title{
Sex and Gender Determinants of Increased Blood Pressure Among Women With Previous Gestational Diabetes Mellitus in Rural China
}

Jia Guo ( $\sim$ guojia621@163.com )

Central South University https://orcid.org/0000-0002-8304-9947

\section{Wencong Lv}

Central South University Xiangya School of Nursing

Shan Jiang

Central South University Xiangya School of Nursing

Yujia Tang

Central South University Xiangya School of Nursing

Qing Long

Central South University Xiangya School of Nursing

Jundi Yang

Central South University Xiangya School of Nursing

James Wiley

University of California San Francisco

Monica Parry

University of Toronto Lawrence S Bloomberg Faculty of Nursing

Research article

Keywords: gestational diabetes mellitus, sex, gender, blood pressure

Posted Date: October 15th, 2020

DOI: https://doi.org/10.21203/rs.3.rs-76957/v1

License: (c) (1) This work is licensed under a Creative Commons Attribution 4.0 International License.

Read Full License 


\section{Abstract}

Background: Gestational diabetes mellitus (GDM) increases the long-term risk of hypertension and cardiovascular events for mothers later in life but has not been well recognized by nurses. The aims of the study were to describe the proportion of increased blood pressure in rural women with previous GDM and to explore the sex (biological) and gender (sociocultural) factors that contribute to the increased blood pressure.

Methods: A cross-sectional descriptive survey including 397 women with previous GDM was conducted in rural areas of Central South of China between November 2017 and June 2018. The variables of sex (e.g., age, ethnicity, family history of hypertension, time since delivery, $75-\mathrm{g}$ oral glucose tolerance test, body mass index, and waist circumference) and gender (education, occupation, income, physical activity, fruit and vegetable intake, sedentary time, perceived stress, and general self-efficacy) were collected on research site. Increased blood pressure referred to systolic blood pressure of $\geq 130 \mathrm{~mm} \mathrm{Hg}$ and/or diastolic blood pressure of $\geq 85 \mathrm{~mm} \mathrm{Hg}$. Logistic regression was performed to recognize the sex and gender factors associated with increased blood pressure.

Results: There were nearly $20 \%$ (78/397) of participants first found increased blood pressure. Among those participants who had increased blood pressure, advanced age, a family history of hypertension, and abnormal 2-h plasma glucose levels were sex-related factors associating with the increased blood pressure $(P<0.05)$, while obesity indicators (body mass index and waist circumference) were not associated $(P>0.05)$. General self-efficacy, a gender factor, had a protective relationship with increased blood pressure $(P<0.05)$.

Conclusions: Increased blood pressure is prevalent in rural Chinese women with previous GDM. Both sex and gender are determinants. Interventions promoting glycemic status and general self-efficacy are promising to improve their cardiovascular health later in life.

\section{Background}

Gestational diabetes mellitus (GDM) refers to glucose intolerance resulting in hyperglycemia which is founded during pregnancy for the first time (1). The prevalence of GDM varies across countries; its reported prevalence is $20 \%$ in Vietnam and Singapore (2), $11.1 \%$ in China (3), and $7.6 \%$ in the United States (4). Overall, the prevalence of GDM has been increasing worldwide (5), which significantly increases the rates of adverse pregnancy and birth outcome (6).

GDM also increases the long-term risk of type 2 diabetes mellitus (T2DM) and cardiovascular disease for mothers later in life (7). The risk of developing T2DM is over seven times higher (8) and the risk of developing hypertension and cardiovascular events is two times higher in women with previous GDM than without (9). Hyperglycemia is associated with increased risk of vascular endothelial injury and hypertension (10), which might interpret the mechanism of the high risk of both T2DM and 
cardiovascular disease among this population. More studies on glycemic status and cardiovascular health after delivery among this population are needed.

Hypertension is one of the main risk factors of cardiovascular disease (11). Nearly $40 \%$ of people aged 25 and over suffered from hypertension all over the world (12). High normal blood pressure, as an important predictor of hypertension (13), refers to systolic blood pressure (SBP) of $130-139 \mathrm{~mm} \mathrm{Hg}$ and/or diastolic blood pressure (DBP) of $85-89 \mathrm{~mm} \mathrm{Hg}(14)$. There was a study reporting that $53 \%$ of adults aged 65-94 years who had baseline clinical high normal blood pressure developed hypertension within four years in the United States (15).

The sex and gender framework emphasizes the collective impact and influence of biological and genetic factors as well as healthy social environment factors on health outcomes and conditions (16). Cardiovascular health as one of the most common health conditions, is determined by both sex (biological) and gender (sociocultural) factors (17). Several sex-related risk factors of developing hypertension in women with GDM, such as ethnicity and advanced age, have been identified. For example, Hispanic women with previous GDM tend to be easier to develop hypertension than Caucasian women (18). In Taiwan, compared with younger women with previous GDM, women at an advanced age had a higher risk for hypertension (19).

Obesity is another important sex factor for the development of cardiovascular disease and related conditions (20). Women with previous GDM are easier to be obese than women with normal glycemic status during pregnancy (21). Obesity-related variables, such as body mass index (BMI) and waist circumference, were associated with hypertension (22). BMI is inversely associated with high-density lipoprotein cholesterol, which positively correlates with the risk of developing hypertension (23).

Gender-related factors, such as health behaviors and psychosocial factors, are closely related to the development of hypertension (24). There is evidence showing that daily physical activity can decrease the risk of hypertension among women (25). Whereas, due to the responsibilities of taking care of children and senior in families for women in rural China, they rarely have time to do enough daily physical activity which is not equal to house work (26).

Diet is another important component of guidelines for antihypertensive therapy in America and Europe (27-29). Fruit and vegetable consumption is negatively associated with increased blood pressure (30). Compared with the nutrition-oriented Western diet, people prefer delicious food in China (31). With the improvement of the economy and social life, the consumption of animal foods and oil/fat has been increased (32). This could be a reason for the increased risk of developing hypertension among the general population. However, the impacts of physical activity and diet on increased blood pressure in rural Chinese women with previous GDM has rarely been reported.

Psychosocial factors also have an influence on the development of hypertension among general women. High levels of perceived stress positively correlate with increased blood pressure among women in France (33). Perceived stress refers to the degree to which people perceive that they cannot meet their needs 
(34). Further, work-related issues present challenges in balancing career and family responsibilities, which often disproportionately increase women's mental stress (35). General self-efficacy refers to a person's confidence in achieving self-management and behavioral change (36). Health behaviors (e.g., healthy dietary habits and physical activity) can be improved by increasing their general self-efficacy among women with previous GDM (37). However, the contribution of general self-efficacy and perceived stress to increased blood pressure among women with previous GDM is not well documented.

To our knowledge, the long-term risk of hypertension and cardiovascular events in this population later in life has not been well recognized by nurses in China. There are few studies exploring the factors associating with increased blood pressure in women with previous GDM from both sex and gender perspectives. The aims of this study were (1) to describe the proportion of rural Chinese women with previous GDM developing increased blood pressure within 4 years after delivery and (2) to explore the association of sex-related factors (age, ethnicity, family history of hypertension, time since delivery, obesity-related factors [BMl and waist circumference], and blood glucose [FBG and 2 h-OGTT]) and gender factors (education, occupation, income, health behaviors [physical activity, vegetable and fruit intake, and sedentary time], and psychosocial factors [stress and general self-efficacy]) with the increased blood pressure.

\section{Methods}

\section{Study Design and Participants}

The study was a cross-sectional survey. The inclusion criteria of the subjects were as follows: (1) diagnosed with GDM during a last pregnancy, (2) age of 18 years or older, (3) postpartum period of six weeks or above, 4) contacted either from family members, friends, or neighbors by telephone, and (5) ability to speak Chinese. The exclusion criteria were as follows: (1) ongoing pregnancy, (2) diagnosed with diabetes before pregnancy or after delivery, (3) previously diagnosed hypertension, or pre-exiting obstetric related hypertension (e.g., preeclampsia and gestational hypertension), (4) physical or cognitive disabilities, (5) current take the blood pressure medicine, or addictive drug abuse (e.g., morphine or cocaine), and (6) severe psychiatric disorders.

Based on 15-30 subjects for each predictor in the logistic regression model, the sample size was calculated (38). Given that there were 15 predictors, the sample size was estimated at 225-450 participants. The final sample size was increased to 467 participants to adjust for a $10 \%$ attrition.

\section{Data Collection}

The participants were recruited from two county-level hospitals (Youxian and Zhangjiajie) of Hunan Province, China between November 2017 and June 2018. Potential participants were identified through a review of the medical records of women who had given birth at the research sites. Local physician or nurse called the candidates who conformed to the inclusion criteria to explain the purpose of the study and determine their willingness to participate. The purpose of the study and confidentiality principles 
were detailed according to standard operating procedures. Informed consent was obtained before the survey was conducted. To avoid participants inadvertently skipping questions, the research assistant checked the questionnaire after they completed. Blood pressure, anthropometric variables (height, weight, and waist circumference), and blood glucose measurements were performed by nurses.

\section{Measurements}

Blood pressure was measured on site by registered nurses using electronic blood pressure monitors (HEM-7120; Omron, Tokyo, Japan) after 12-h fasting according to the criteria of the Chinese Hypertension League/National Center (39). Blood pressure was divided into two categories according to the criteria of the European Society of Cardiology and the European Society of Hypertension as follows: normal blood pressure (SBP $<130 \mathrm{~mm} \mathrm{Hg}$ and $\mathrm{DBP}<85 \mathrm{~mm} \mathrm{Hg}$ ) and increased blood pressure (high normal blood pressure: SBP $\geq 130 \mathrm{~mm} \mathrm{Hg}$ and/or DBP $\geq 85 \mathrm{~mm} \mathrm{Hg}$, and hypertension: $\mathrm{SBP} \geq 140 \mathrm{~mm} \mathrm{Hg}$ and/or DBP $\geq 90 \mathrm{~mm} \mathrm{Hg})(14)$.

Partial sex (e.g., age, ethnicity, family history of hypertension, and time after delivery) and gender data (e.g., education, occupation, and monthly family income) were collected via a self-designed questionnaire. Ethnicity was categorized as Han and minority. According to the major periods for discerning glucose metabolic abnormality reported by previous studies, the time since delivery was classified into four categories: $\leq 3$ months, $>3$ to $\leq 12$ months, $>12$ to $\leq 36$ months, and $>36$ months (40, 41). Education was categorized as junior high school and below ( $<12$ years of schooling) and senior high school and above ( $\geq 12$ years of schooling). Occupation status was categorized as employed and unemployed. Based on the poverty line in China, poverty was defined as a monthly family income of less than $\$ 145$ (42). Accordingly, the monthly family income was divided into $<\$ 145$ and $\geq \$ 145$.

Sex-related variables also included obesity related factors (i.e., BMI and waist circumference) and blood glucose. Obesity-related anthropometric measurements included BMI and waist circumference. The BMI was calculated as weight in kilograms divided by height in meters squared and categorized into two levels based on the guidelines for the prevention and control of overweight and obesity in Chinese adults: underweight or normal $(<24 \mathrm{~kg} / \mathrm{m} 2)$ and overweight or obese ( $\geq 24 \mathrm{~kg} / \mathrm{m} 2)(43)$. According to criteria of the International Diabetes Federation (44) and the National Institute for Health and Care Excellence (25), waist circumference was divided into normal $(<80 \mathrm{~cm})$ and central obese $(\geq 80 \mathrm{~cm})$.

Blood glucose included fasting blood glucose (FBG) and two-hour oral glucose tolerance tests ( $2 \mathrm{~h}$ OGTT). After overnight fasting, venous blood samples were collected to measure the FBG. For the $2 \mathrm{~h}-$ OGTT, blood samples were collected after 12-h fasting followed by blood samples taken $2 \mathrm{~h}$ after consumption of $75 \mathrm{~g}$ of glucose. The hexokinase enzyme method was used to measure the blood glucose.

Gender-related variables included health behaviors (physical activity, vegetable and fruit intake, and sedentary time) and psychosocial factors (stress and general self-efficacy). Physical activity was measured by the following item of the Chinese version of the Canadian Diabetes Risk Questionnaire, 
which was developed by Robinson, Agarwal, and Nerenberg (45) and revised and translated into Chinese by Guo (46): "Do you engage in a regular physical activity, such as brisk walking for at least 30 minutes each day?" The daily vegetable and fruit intake was measured by the following item: "Do you eat vegetables or fruits every day?". The Chinese Diabetes Risk Questionnaire has good reliability and validity (46).

Sedentary time was measured by the following item of the short form of the International Physical Activity Questionnaire (IPAQ-S) (Chinese version) (47): "How much time did you usually spend sitting?" The IPAQ-S has an intraclass correlation coefficient greater than 0.70 .

Stress was measured by the Perceived Stress Scale, which was designed to access the level of stress in life (48). This scale, including 14 items, was revised and translated into Chinese (49). The total score ranges from 0 to 56, with a score of 26 means high level stress(49). This scale has good internal consistency reliability with Cronbach's a coefficient of 0.78 (49).

General self-efficacy was measured by the General Self-Efficacy Scale (Chinese version) (50), which includes 10 items. Higher scores indicates better general self-efficacy, and the score ranges from 10 to 40 . The internal consistency coefficient of the scale was 0.87 (50).

\section{Data Analysis}

Data analyses were performed by IBM SPSS Statistics 23. Descriptive statistics were computed to describe the sample. The associations between sex and gender variables and increased blood pressure were determined by one-way analysis of variance (ANOVA) and chi-squared tests. In order to identify factors influencing increased blood pressure, multivariate logistic regression was conducted. The covariates of the logistic regression were selected based on the bivariate analysis (one-way ANOVA or chisquared tests) and previous literature (e.g., ethnicity, obesity-related variables, FBG, education, income, occupation, stress, and lifestyle behaviors). A P value less than 0.05 was considered statistically significant.

\section{Results}

This survey recruited 467 women. Of those, 70 were excluded because they did not complete either the 2h 75-g OGTT ( $n=40,8.6 \%)$ or the questionnaire $(n=30,6.4 \%)$. Consequently, 397 women $(85.0 \%$ recruitment yield) were included. There were no significant differences in sex and gender-related data (e.g., age, ethnicity, education, occupation, monthly family income, and time since delivery) between the included and excluded participants $(P>0.05)$.

The power of the current sample size was examined by a post-hoc power analysis. Assuming an a of 0.05 , a base prevalence of 0.20 , and the R-squared with other predictors is of 0.50 , a two-tailed test of the null hypothesis of an odds ratio (OR) of 1.0 for a given predictor against an alternative odds ratio of 1.70 has a power of 0.83 in a logistic regression with $\mathrm{N}=397$ (G*Power 3.1). 


\section{Distribution of Blood Pressure Among Rural Women With Previous GDM}

Nearly $20 \%(n=78)$ of the women had increased blood pressure, of whom $30.7 \%(n=24)$ had hypertension and $69.3 \%(n=54)$ had high normal blood pressure. Of the 397 participants, $80.3 \%$ of the women $(n=319)$ had normal blood pressure. The mean SBP of high normal blood pressure were $129.11 \mathrm{~mm} \mathrm{Hg}$ (SD 6.46), while the mean DBP was $80.72 \mathrm{~mm} \mathrm{Hg}$ (SD 7.91). The details of the participants' blood pressure distribution are displayed in Table 1.

Table 1

Distribution of Blood pressure among rural women with previous GDM

\begin{tabular}{|llllll|}
\hline Blood pressure & \multicolumn{3}{l}{ SBP } & \multicolumn{3}{l|}{ DBP } \\
\cline { 2 - 6 } N (\%) & & Mean \pm SD & Range & Mean \pm SD & range \\
\hline Normal & $319(80.3)$ & $112.29 \pm 8.38$ & $90-129$ & $71.24 \pm 7.64$ & $46-84$ \\
\hline High Normal & $54(13.7)$ & $129.11 \pm 6.46$ & $114-139$ & $80.72 \pm 7.91$ & $57-89$ \\
\hline Hypertension & $24(6.0)$ & $139.25 \pm 11.22$ & $120-170$ & $92.75 \pm 7.57$ & $78-113$ \\
\hline Abbreviations:; SD, standard deviation. & & & \\
\hline
\end{tabular}

The participants' mean age was 32.27 years (SD 5.2), with a range of $20-47$ years. And $45.8 \%$ of the participants $(n=182)$ were Minority nationality. One-third $(n=137,33.2 \%)$ had a family history of hypertension.

The mean time since delivery was 15.50 months (SD 12.46). Nearly a fifth $(n=73,18.4 \%)$ of the participants had given birth less than 3 months previously, more than one-third $(n=136,34.3 \%) 3-12$ months previously, approximately $37.8 \%(n=150) 12-36$ months previously, and $9.5 \%(n=38)$ over 36 months previously. Among the 78 women with increased blood pressure, more than a fifth $(n=18,23.1 \%)$ had given birth less than 3 months previously, one-third $(n=27,34.6 \%) 3-12$ months previously, 35.9\% (n $=28) 12-36$ months previously, and $6.4 \%(n=5)$ over 36 months previously.

The mean BMI was $23.85 \mathrm{~kg} / \mathrm{m} 2$ (SD 3.65) and $45.8 \%(\mathrm{n}=182)$ of the participants being overweight or obese ( $\geq 24.0 \mathrm{~kg} / \mathrm{m} 2)$. The mean waist circumference was $80.33 \mathrm{~cm}$ (SD 8.50) with $52.4 \%(\mathrm{n}=208)$ of the participants characterized by central obesity $(>80 \mathrm{~cm})$.

The mean FBG level was $5.35 \mathrm{mmol} / \mathrm{L}$ (SD 1.28) with $10.7 \%$ of the participants exhibiting FBG levels higher than $6.1 \mathrm{mmol} / \mathrm{L}$. The mean $2 \mathrm{~h}-\mathrm{OGTT}$ was $6.55 \mathrm{mmol} / \mathrm{L}$ (SD 2.69) with $15.1 \%(\mathrm{n}=60)$ of the participants having glucose intolerance $(2 \mathrm{~h}-\mathrm{OGTT}>7.8 \mathrm{mmol} / \mathrm{L})$. Details of the participants' sex characteristics are displayed in Table 2. 
Table 2

Sex and gender characteristics of rural women with previous GDM according to blood pressure $(\mathrm{N}=397)$

$\begin{array}{llllll}\text { Variables } & \text { Total } & \text { Normal } & H N \& H & X^{2} / t & \begin{array}{l}P \text { - } \\ \text { value }\end{array} \\ & N(\%) & N=319 & N=78 & & \end{array}$

\section{Sex characteristics}

Age, mean(SD)

$31.83(4.93) \quad 34.05(5.98) \quad-3.038 \quad 0.003$

Ethnic

$1.455 \quad 0.228$

Minority

182(45.8) 151(47.3) 31(39.7)

Han

215(54.2) $\quad$ 168(52.7) $\quad 47(60.3)$

Family History of Hypertension

$10.307 \quad 0.001$

$\begin{array}{llll}\text { Yes } & 137(33.2) & 98(30.7) & 39(50.0) \\ \text { No } & 260(66.3) & 221(69.3) & 39(50.0)\end{array}$

Time after delivery

$\begin{array}{llll}\leq 3 \text { months } & 73(18.4) & 55(17.2) & 18(23.1) \\ \begin{array}{l}>3 \text { to } \leq \\ 12 \text { months }\end{array} & 136(34.3) & 109(34.2) & 27(34.6) \\ \begin{array}{l}>12 \text { to } \leq \\ 36 \text { months }\end{array} & 150(37.8) & 122(38.2) & 28(35.9) \\ >36 \text { months } & 38(9.5) & 33(10.4) & 5(6.4)\end{array}$

BMI

\begin{tabular}{lccc}
$\begin{array}{l}\text { Underweight or } \\
\text { normal }\end{array}$ & $215(54.2)$ & $177(55.5)$ & $38(48.7)$ \\
$\begin{array}{l}\text { Overweight or } \\
\text { obese }\end{array}$ & $182(45.8)$ & $142(44.5)$ & $40(51.3)$ \\
\hline
\end{tabular}

Waist

circumference

Normal

Obese

FBG

$$
\begin{aligned}
& <6.1 \\
& \geq 6.1
\end{aligned}
$$

189(47.6)

208(52.4)

$\begin{array}{llll}<6.1 & 354(89.1) & 287(90.0) & 67(85.9) \\ \geq 6.1 & 43(10.9) & 32(10.0) & 11(14.1)\end{array}$

Abbreviations: GDM, gestational diabetes mellitus; FBG, fasting blood glucose; $2 \mathrm{~h}-\mathrm{OGTT}$, two-hour oral glucose tolerance tests; BMI, body mass index; SD, standard deviation. 


\begin{tabular}{|c|c|c|c|c|c|}
\hline \multirow[t]{2}{*}{ Variables } & Total & Normal & $H N \& H$ & \multirow[t]{2}{*}{$x^{2} / t$} & \multirow{2}{*}{$\begin{array}{l}\mathrm{P}- \\
\text { value }\end{array}$} \\
\hline & $N(\%)$ & $N=319$ & $N=78$ & & \\
\hline 2 h-OGTT & & & & 12.969 & 0.000 \\
\hline$<7.8$ & $337(84.9)$ & 281(88.1) & $56(71.8)$ & & \\
\hline$\geq 7.8$ & $60(15.1)$ & $38(11.9)$ & $22(28.2)$ & & \\
\hline \multicolumn{6}{|l|}{ Gender characteristics } \\
\hline Education & & & & 3.675 & 0.054 \\
\hline $\begin{array}{l}\text { Junior high } \\
\text { school and below }\end{array}$ & $94(23.7)$ & $68(21.3)$ & $26(33.3)$ & & \\
\hline $\begin{array}{l}\text { Senior high } \\
\text { school and above }\end{array}$ & $303(76.3)$ & 251(78.7) & $52(66.7)$ & & \\
\hline Occupation & & & & 0.016 & 0.898 \\
\hline Employed & $252(63.5)$ & 202(63.3) & $50(64.1)$ & & \\
\hline Unemployed & $145(36.5)$ & $117(36.7)$ & 28(35.9) & & \\
\hline Monthly Family Income & & & & 0.225 & 0.636 \\
\hline$<145 \$$ & $12(3.0)$ & $9(2.8)$ & $3(3.8)$ & & \\
\hline$\geq 145 \$$ & $385(97.0)$ & $310(97.2)$ & $75(96.2)$ & & \\
\hline Regularly physical activity & & & & 0.909 & 0.340 \\
\hline Yes & 130(32.9) & 108(33.9) & $22(28.2)$ & & \\
\hline No & 267(67.3) & $211(66.1)$ & $56(71.7)$ & & \\
\hline Daily vegetables and fruit intake & & & & 0.999 & 0.318 \\
\hline Yes & $77(19.4)$ & $65(20.3)$ & 12(15.4) & & \\
\hline No & $320(80.6)$ & $254(79.7)$ & $66(84.6)$ & & \\
\hline Sedentary time & & & & 1.772 & 0.183 \\
\hline$<6 \mathrm{~h}$ & $279(70.2)$ & 229(71.7) & $50(64.1)$ & & \\
\hline$\geq 6 \mathrm{~h}$ & $118(29.7)$ & $90(28.2)$ & $28(35.9)$ & & \\
\hline General self-efficacy & 25.81(5.89) & $26.19(5.85)$ & $24.27(5.83)$ & 2.601 & 0.010 \\
\hline $\begin{array}{l}\text { Perceived } \\
\text { stress }\end{array}$ & $23.93(6.40)$ & $23.72(6.67)$ & $24.66(5.11)$ & -1.532 & 0.128 \\
\hline $\begin{array}{l}\text { Abbreviations: GDM, gestational diab } \\
\text { oral glucose tolerance tests; BMI, bod }\end{array}$ & $\begin{array}{l}\text { s mellitus; } F I \\
\text { רass index; } S\end{array}$ & $\begin{array}{l}\text { fasting blo } \\
\text { standard de }\end{array}$ & $\begin{array}{l}\text { glucose; } 2 \mathrm{~h}- \\
\text { tion. }\end{array}$ & STT, tw & \\
\hline
\end{tabular}




\section{Gender Characteristics Among Rural Women With Previous GDM}

Of the 397 participants, $76.3 \%(n=303)$ had completed more than 12 years of education, and $97.0 \%(n=$ 385 ) had a monthly family income above the Chinese poverty threshold (i.e., $\geq \$ 145$ ). Approximately $36.5 \%(n=145)$ of women were unemployed.

More than two-thirds ( $n=267,67.3 \%$ ) of the participants engaged in physical activities for less than 30 min a day. Most participants $(n=320,80.6 \%)$ did not consume fruit or vegetables every day, and more than two-thirds $(n=279,70.2 \%)$ reported a sedentary time less than $6 \mathrm{~h}$ every day.

The mean perceived stress score was 23.92 (SD 6.40), with a range of 1-39. Of the 397 participants, $37.8 \%$ reported high stress levels. The mean score of general self-efficacy was 25.81 (SD 5.89), with a range of 10-40. The details of the participants' gender characteristics are displayed in Table 2.

\section{Bivariate Analysis of Sex and Gender Factors and Increased Blood Pressure Among Rural Women With Previous GDM}

Women with increased blood pressure were older than women with normal blood pressure $(P=0.003)$; Compared with those without family history of hypertension, women with a family history had higher rates of increased blood pressure ( $P=0.001)$; and women with high $2 \mathrm{~h}$-OGTT values had higher rates of increased blood pressure than those with normal 2 h-OGTT values $(P=0.001)$. There were no statistically significant differences in blood pressure related to ethnicity, time since delivery, obesity-related variables (BMI and waist circumference), and FBG between the participants $(P>0.05)$.

Bivariate analysis of gender variables indicated that women reporting lower self-efficacy had higher rates of increased blood pressure than those with higher self-efficacy $(P=0.012)$. There were no significant association between blood pressure and other gender variables (education, income, occupation, health behaviors [physical activity, fruit and vegetable intake, and sedentary time], and perceived stress) between the participants $(P>0.05)$.

\section{Logistic Regression of Increased Blood Pressure Among Rural Women With Previous GDM}

As shown in Table 3, women at an advanced age and those with a family history of hypertension more tend to develop blood pressure (OR: 1.070, 95\% confidence interval [CI]: 1.015-1.128 and OR: 1.934, 95\% Cl: 1.128-3.317, respectively; $\mathrm{P}<0.05)$. Similarly, women with abnormal $2 \mathrm{~h}-0 \mathrm{GTT}$ values had a higher risk of developing increased blood pressure (OR: 2.042, 95\% Cl: 1.053-3.958; $\mathrm{P}<0.05)$. Moreover, selfefficacy was negatively related to increased blood pressure (OR:1.070, 95\% Cl: 1.015-1.128; $\mathrm{P}<0.05$ ). The results of the logistic regression analyses are displayed in Table 3. 
Table 3

Logistic regression of blood pressure among rural women with previous GDM

\begin{tabular}{|llll|}
\hline Variables & OR & Cl & P value \\
\hline Sex & & & \\
\hline Age(year) & 1.070 & $1.015-1.128$ & 0.011 \\
\hline Ethnicity (vs Han) & 0.796 & $0449-1.409$ & 0.433 \\
\hline Family history of hypertension (vs no) & 1.934 & $1.128-3.317$ & 0.017 \\
\hline Time since delivery (vs $\leq 3$ 3months) & 0.921 & $0.682-1.243$ & 0.590 \\
\hline BMI (vs underweight or normal) & 1.125 & $0.535-2.366$ & 0.757 \\
\hline Waist circumference (vs normal) & 1.075 & $0.516-2.241$ & 0.847 \\
\hline 2 h-OGTT (vs < 7.8) & 2.042 & $1.053-3.958$ & 0.035 \\
\hline FBG (vs <6.1) & 1.304 & $0.586-2.901$ & 0.516 \\
\hline Gender & & & \\
\hline Education (vs Junior high school and below) & 0.628 & $0.341-1.156$ & 0.135 \\
\hline Monthly Family Income (vs > 145\$) & 1.471 & $0.321-6.730$ & 0.619 \\
\hline Occupation (vs unemployed) & 1.029 & $0.582-1.818$ & 0.922 \\
\hline Vegetables and fruits (vs yes) & 0.971 & $0.465-2.030$ & 0.938 \\
\hline Sedentary time(vs < 6h) & 1.382 & $0.781-2.445$ & 0.266 \\
\hline Physical activity (vs no) & 0.757 & $0.418-1.370$ & 0.358 \\
\hline Perceived stress & 1.003 & $0.956-1.052$ & 0.917 \\
\hline Self-efficacy & 1.070 & $1,015-1.128$ & 0.031 \\
\hline $\begin{array}{l}\text { Abbreviations: GDM, gestational diabetes mellitus; BMI, body mass index; } 2 \text { h-0GTT, two-hour oral } \\
\text { glucose tolerance tests; FBG, fasting blood glucose. }\end{array}$ & & \\
\hline
\end{tabular}

\section{Discussion}

This cross-sectional survey involving 397 women obtained several key findings. First, at a mean time of 15.5 months after delivery, the prevalence of increased blood pressure among rural Chinese women with previous GDM was nearly $20 \%$. Second, both sex and gender determinants were identified, such as advanced age, family history of hypertension, and low general self-efficacy. Surprisingly, in this sample, obesity indicators (BMI or waist circumference) were not significantly related to increased blood pressure, while abnormal 2 h-OGTT was an important associating factor. 
The proportion of increased blood pressure in this study (19.6\%) is similar to that of Spanish women with previous GDM (20\%) (51) and slightly higher than that of Chinese women without GDM (16.9\%) (52). The majority (90.5\%) of women with increased blood pressure had given birth less than 36 months previously. This early development of increased blood pressure among women with previous GDM is alarming.

Regarding sex factors, women at an advanced age had a higher risk of increased blood pressure after delivery, which is consistent with findings concerning women with previous GDM in Taiwan (19). This might be because the metabolic and vascular environment deteriorate with age, thus increasing the risk of increased blood pressure (53). In this study, women with a family history of hypertension had a higher risk for increased blood pressure after delivery, which is consistent with findings regarding general populations in the US and Japan $(54,55)$.

Furthermore, women with abnormal 2 h-OGTT but not FBG were more likely to develop increased blood pressure, which is consistent with findings regarding women with previous GDM in Finland (56). Compared with abnormal FBG, abnormal glucose tolerance (e.g., 2 h-OGTT) leads to faster insulin resistance. This increases cardiac output and vascular resistance, ultimately leading to increased blood pressure (57).

Unexpectedly, in this study, neither BMI nor waist circumference was significantly related to increased blood pressure after delivery. This finding is inconsistent with previous studies on urban Chinese women with previous GDM (58), suggesting that obesity indicators may be risk factors for increased blood pressure among women with previous GDM in some regions but not in rural areas of central-south China. Other factors may be more important for the increased blood pressure in this population.

General self-efficacy was the only gender factor related to increased blood pressure. Women with greater general self-efficacy were less likely to develop hypertension after delivery. It has been reported that among American adults, high self-efficacy is strongly associated with confidence and the motivation to engage in activities related to reducing hypertension among American adults (59). Accordingly, women with greater self-efficacy in our study may pursue healthy behaviors and coping strategies that reduce the risk of hypertension $(37,60)$.

There was no relationship between perceived stress and increased blood pressure after delivery. This is consistent with findings regarding a general adult population (61). This might be because short-term or relatively low levels of stress are unlikely to have sustained effects on behavioral and pathophysiological processes that contribute to hypertension $(62,63)$. To confirm this hypothesis, longitudinal cohort studies exploring the association between blood pressure and perceived stress among women with previous GDM are needed.

\section{Limitations}

Several limitations existed in our study. First, the difference of postpartum period, the according variation in glucose metabolism and perhaps influence the blood pressure of women. Another limitation is related 
to the fact that a standard approach to measuring gender-related variables was not used. In fact, a lot of work is now being done to determine exactly what gender is and how it can be measured. The GENESISPRAXY questionnaire could be used in future studies. In this study, it might not be that variations exist by geography, but by gender and this can be evaluated in a future study using a better measurement of gender. Third, response bias cannot be ruled out in survey with self-reported questionnaires. Finally, the generality of our results may be limited, because all sample were enrolled in Hunan Province.

\section{Implications}

Despite its limitations, this study has several important clinical implications for preventing increased blood pressure among rural Chinese women with GDM. First, raising consciousness of risk for increased blood pressure in rural Chinese women with previous GDM is indicated. Nurses should pay particular attention to women at an advanced age and those with a family history of hypertension. Targeting these women will ensure that they are aware of their increased risk. Moreover, health-care providers must ensure that blood pressure and blood glucose levels are adequately followed up.

Furthermore, interventions aimed at preventing the development of increased blood pressure in women with previous GDM are needed. Promoting health behavior-related general self-efficacy by mastering tasks or skills, exchanging experiences, and setting goals related to blood pressure $(14,64)$ and maintaining normal blood glucose levels by changing dietary habits (e.g., increasing the intake of fruit and vegetables and reducing the intake of food with high-fat and sugary) (65) are recommended. Finally, studies investigating more potentially influencing factors in more geographic locations and different cultural contexts are needed for this special population.

\section{Conclusions}

The early development of increased blood pressure in rural Chinese women with previous GDM is alarming. Both sex and gender factors are contributors. Strategies aimed at maintaining normal blood glucose tolerance and optimal general self-efficacy are crucial for reducing this risk for rural Chinese women with previous GDM, especially those at an advanced age and those with a family history of hypertension.

\section{Abbreviations}

GDM, gestational diabetes mellitus; FBG, fasting blood glucose; 2 h-OGTT, two-hour oral glucose tolerance tests; BMI, body mass index; SBP, Systolic blood pressure; DBP, Diastolic blood pressure.

\section{Declarations}

\section{Funding}


Supported by China Medical Board (Grant Number: 16-256), Huxiang Youth Science and Technology Innovation Talents (Grant No.2019RS2006) and The Key Laboratory of Hunan Province (Grant No. 2017TP1004).

\section{Author Contributions}

Jia Guo designed the current study. Wencong Lv and Shan Jiang jointly defined the analytic strategy and analyzed the data. Wencong Lv drafted the manuscript. Jia Guo, Shan Jiang, Yujia Tang, Jundi Yang and Qing Long collected data. Jia Guo, Monica Parry and James Wiley reviewed and edited the manuscript. All authors have read and agreed to the final version of the manuscript.

\section{Acknowledgments}

Not applicable.

\section{Availability of data and materials}

The datasets used and/or analyzed during the current study are available from the corresponding author on reasonable request.

\section{Ethics approval and consent to participate}

The Nursing and Behavioral medicine Institutional Review Board of Xiangya Nursing School of Central South University have granted ethical approval to the study (No. 2016034). Written informed consent is collected from participants in accordance with our IRB-approved protocol.

\section{Consent for publication}

Not applicable.

\section{Competing interests}

The authors declare that they have no competing interests.

\section{References}

1. Diagnosis and Classification of Diabetes Mellitus. Diabetes Care. 2012;35(1):S64-S71.

2. Xiong X, Elkind-Hirsch KE, Xie Y, Delarosa R, Maney P, Pridjian G, et al. Periodontal disease as a potential risk factor for the development of diabetes in women with a prior history of gestational diabetes mellitus. Journal of Public Health Dentistry. 2013;73(1):41-9.

3. Mai C, Hou M, Chen R, Duan D, Xu H, Lin X, et al. Cardiovascular risk factors in Chinese women with a history of gestational diabetes mellitus. International Journal of Clinical and Experimental Medicine. 2015;8(11):21694-8. 
4. Casagrande SS, Linder B, Cowie CC. Prevalence of gestational diabetes and subsequent Type 2 diabetes among US women. Diabetes Research and Clinical Practice. 2018;141:200-8.

5. Gestational diabetes mellitus. Diabetes Care. 2000;23:S77-S9.

6. Natamba BK, Namara AA, Nyirenda MJ. Burden, risk factors and maternal and offspring outcomes of gestational diabetes mellitus (GDM) in sub-Saharan Africa (SSA): a systematic review and metaanalysis \%J BMC Pregnancy and Childbirth. 2019;19(4).

7. Shostrom DCV, Sun Y, Oleson JJ, Snetselaar LG, Bao W. History of Gestational Diabetes Mellitus in Relation to Cardiovascular Disease and Cardiovascular Risk Factors in US Women. Frontiers in Endocrinology. 2017;8.

8. Bellamy L, Casas J-P, Hingorani AD, Williams D. Type 2 diabetes mellitus after gestational diabetes: a systematic review and meta-analysis. Lancet. 2009;373(9677):1773-9.

9. Kramer CK, Campbell S, Retnakaran R. Gestational diabetes and the risk of cardiovascular disease in women: a systematic review and meta-analysis \%J Diabetologia. 2019;62(6).

10. Mirrahimi A, de Souza RJ, Chiavaroli L, Sievenpiper JL, Beyene J, Hanley AJ, et al. Associations of glycemic index and load with coronary heart disease events: a systematic review and meta-analysis of prospective cohorts. J Am Heart Assoc. 2012;1(5):e000752.

11. Kearney PM, Whelton M, Reynolds K, Muntner P, Whelton PK, He J. Global burden of hypertension: analysis of worldwide data. Lancet. 2005;365(9455):217-23.

12. Idiculla T, Zachariah G, Br K, Mohamood $\mathrm{N}$. The incidence and prevalance of idiopathic intracranial hypertension in south Sharaqiah region, Oman. Oman journal of ophthalmology. 2013;6(3):189-92.

13. Freiberg MS, Chang Y-F, Kraemer KL, Robinson JG, Adams-Campbell LL, Kuller LL. Alcohol Consumption, Hypertension, and Total Mortality Among Women. American Journal of Hypertension. 2009;22(11):1212-8.

14. Williams B, Mancia G, Spiering W, Agabiti Rosei E, Azizi M, Burnier M, et al. 2018 ESC/ESH Guidelines for the management of arterial hypertension: The Task Force for the management of arterial hypertension of the European Society of Cardiology and the European Society of Hypertension: The Task Force for the management of arterial hypertension of the European Society of Cardiology and the European Society of Hypertension. J Hypertens. 2018;36(10):1953-2041.

15. Tsao CW, Vasan RS. Cohort Profile: The Framingham Heart Study (FHS): overview of milestones in cardiovascular epidemiology. International Journal of Epidemiology. 2015;44(6):1800-13.

16. Canadian Institutes of Health Research (CIHR). Gender, sex, and health research guide: a tool for ClHR applicants. Ottawa. 2014. http://www.cihr-irsc. gc.ca/e/32019.html.

17. O'Neil A, Scovelle AJ, Milner AJ, Kavanagh A. Gender/Sex as a Social Determinant of Cardiovascular Risk. Circulation. 2018;137(8):854-64.

18. Bentley-Lewis R, Powe C, Ankers E, Wenger J, Ecker J, Thadhani R. Effect of Race/Ethnicity on Hypertension Risk Subsequent to Gestational Diabetes Mellitus. American Journal of Cardiology. 2014;113(8):1364-70. 
19. Hwu L-J, Sung F-C, Mou C-H, Wang IK, Shih H-H, Chang Y-Y, et al. Risk of Subsequent Hypertension and Diabetes in Women With Hypertension During Pregnancy and Gestational Diabetes. Mayo Clinic Proceedings. 2016;91(9):1158-65.

20. Gaillard R. Maternal obesity during pregnancy and cardiovascular development and disease in the offspring. European Journal of Epidemiology. 2015;30(11):1141-52.

21. Ratner RE. Prevention of type 2 diabetes in women with previous gestational diabetes. Diabetes Care. 2007;30:S242-S5.

22. Hauspurg A, Countouris ME, Jeyabalan A, Hubel CA, Roberts JM, Schwarz EB, et al. Risk of hypertension and abnormal biomarkers in the first year postpartum associated with hypertensive disorders of pregnancy among overweight and obese women. Pregnancy Hypertension-an International Journal of Womens Cardiovascular Health. 2019;15:1-6.

23. Barter PJ. The causes and consequences of low levels of high density lipoproteins in patients with diabetes. Diabetes \& metabolism journal. 2011;35(2):101-6.

24. Diaz KM, Shimbo D. Physical Activity and the Prevention of Hypertension. Current Hypertension Reports. 2013;15(6):659-68.

25. Hegde SM, Solomon SD. Influence of Physical Activity on Hypertension and Cardiac Structure and Function. Current Hypertension Reports. 2015;17(10).

26. Qiao F, Rozelle S, Zhang L, Yao Y, Zhang J. Impact of Childcare and Eldercare on Off-farm Activities in Rural China. China \& World Economy. 2015;23(2):100-20.

27. Mancia G, Fagard R, Narkiewicz K, Redon J, Zanchetti A, Boehm M, et al. 2013 ESH/ESC Guidelines for the management of arterial hypertension. European Heart Journal. 2013;34(28):2159-219.

28. James PA, Oparil S, Carter BL, Cushman WC, Dennison-Himmelfarb C, Handler J, et al. 2014 Evidence-Based Guideline for the Management of High Blood Pressure in Adults Report From the Panel Members Appointed to the Eighth Joint National Committee (JNC 8). Jama-Journal of the American Medical Association. 2014;311(5):507-20.

29. Mendis S, Davis S, Norrving B. Organizational Update The World Health Organization Global Status Report on Noncommunicable Diseases 2014; One More Landmark Step in the Combat Against Stroke and Vascular Disease. Stroke. 2015;46(5):E121-E2.

30. Graudal NA, Hubeck-Graudal T, Jurgens G. Effects of low sodium diet versus high sodium diet on blood pressure, renin, aldosterone, catecholamines, cholesterol, and triglyceride. Cochrane Database of Systematic Reviews. 2017(4).

31. Yu Y. The Analysis of Diet Culture Differences between China and Western Countries. 2016 Issgbm International Conference on Information, Communication and Social Sciences. Lecture Notes in Management Science. 692016. p. 504-7.

32. W Z, J C. Implications from and for food cultures for cardiovascular disease: diet, nutrition and cardiovascular diseases in China. \%J Asia Pacific journal of clinical nutrition. 2001;10(2).

33. Emmanuel W, Hermann N, Bruno P, Sébastien C, Olivier H, Tabassome S, et al. Perceived stress, sex and occupational status interact to increase the risk of future high blood pressure: the IPC cohort 
study. \%J Journal of hypertension. 2014;32(10).

34. Lee E-H. Review of the Psychometric Evidence of the Perceived Stress Scale. Asian Nursing Research. 2012;6(4):121-7.

35. Clougherty JE, Eisen EA, Slade MD, Kawachi I, Cullen MR. Gender and sex differences in job status and hypertension. Occupational and Environmental Medicine. 2011;68(1):16-23.

36. Kim C, McEwen LN, Kieffer EC, Herman WH, Piette JD. Self-efficacy, social support, and associations with physical activity and body mass index among women with histories of gestational diabetes mellitus. Diabetes Educator. 2008;34(4):719-28.

37. Pinidiyapathirage J, Jayasuriya R, Cheung NW, Schwarzer R. Self-efficacy and planning strategies can improve physical activity levels in women with a recent history of gestational diabetes mellitus. Psychology \& Health. 2018;33(8):1062-77.

38. Palmer PB, O'Connell DG. Regression analysis for prediction: understanding the process. Cardiopulmonary physical therapy journal. 2009;20(3):23-6.

39. Kleman M, Dhanyamraju S, DiFilippo W. Prevalence and characteristics of pseudohypertension in patients with "resistant hypertension". Journal of the American Society of Hypertension. 2013;7(6):467-70.

40. Anonymous. 14. Management of Diabetes in Pregnancy: Standards of Medical Care in Diabetes2019 \%J Diabetes Care. 2019;42.

41. Benhalima K, Lens K, Bosteels J, Chantal M. The Risk for Glucose Intolerance after Gestational Diabetes Mellitus since the Introduction of the IADPSG Criteria: A Systematic Review and MetaAnalysis \%J Journal of Clinical Medicine. 2019;8(9).

42. Sisi Ma, Zhanming Jin., Per Capita Disposable Income of Rural Resident in China. Technology Economics 2018, 37(10),131-137.

43. Chen C, Lu FC. The guidelines for prevention and control of overweight and obesity in Chinese adults. Biomedical and environmental sciences : BES. 2004;17 Suppl:1-36.

44. Alberti KGMM, Zimmet P, Shaw J. International Diabetes Federation: a consensus on Type 2 diabetes prevention. Diabetic Medicine. 2007;24(5):451-63.

45. Robinson CA, Agarwal G, Nerenberg K. Validating the CANRISK prognostic model for assessing diabetes risk in Canada's multi-ethnic population. Chronic Diseases and Injuries in Canada. 2011;32(1):19-31.

46. Guo J, Shi Z, Chen J-L, Dixon JK, Wiley J, Parry M. Translation and validation of the Canadian diabetes risk assessment questionnaire in China. Public Health Nursing. 2018;35(1):18-28.

47. Qu NN, Li KJ. [Study on the reliability and validity of international physical activity questionnaire (Chinese Vision, IPAQ)]. Zhonghua Liu Xing Bing Xue Za Zhi. 2004;25(3):265-8.

48. Cohen S, Kamarck T, Mermelstein R. A global measure of perceived stress. Journal of health and social behavior. 1983;24(4):385-96. 
49. Yang T-z, Huang H-t. [An epidemiological study on stress among urban residents in social transition period]. Zhonghua liu xing bing xue za zhi = Zhonghua liuxingbingxue zazhi. 2003;24(9):760-4.

50. Barlow JH, Williams B, Wright C. The Generalized Self-Efficacy Scale in people with arthritis. Arthritis care and research : the official journal of the Arthritis Health Professions Association. 1996;9(3):18996.

51. Atkins EV, Sambamoorthi U, Bhattacharya R. Variations of Depression Treatment Among Women With Hypertension. Health Care for Women International. 2015;36(6):730-50.

52. Al Fattah AN, Putri AK, Prakoso R, Irwinda R, Wibowo N, Santoso BI. Delivery Outcome among Pregnant Women with Hypertension. Journal of Hypertension. 2015;33:E13-E.

53. Retnakaran R, Shah BR. Role of Type 2 Diabetes in Determining Retinal, Renal, and Cardiovascular Outcomes in Women With Previous Gestational Diabetes Mellitus. Diabetes Care. 2017;40(1):101-8.

54. Liu J, Sekine M, Tatsuse T, Hamanishi S, Fujimura Y, Zheng X. Family history of hypertension and the risk of overweight in Japanese children: results from the Toyama Birth Cohort Study. J Epidemiol. 2014;24(4):304-11.

55. M PC, C MJ, E SK, T PE, A CM, Seongkum H, et al. Perceptions of family history and genetic testing and feasibility of pedigree development among African Americans with hypertension. \%J European journal of cardiovascular nursing : journal of the Working Group on Cardiovascular Nursing of the European Society of Cardiology. 2015;14(1).

56. Pirkola J, Pouta A, Bloigu A, Miettola S, Hartikainen A-L, Jarvelin M-R, et al. Prepregnancy Overweight and Gestational Diabetes as Determinants of Subsequent Diabetes and Hypertension after 20-Year Follow-Up. Journal of Clinical Endocrinology \& Metabolism. 2010;95(2):772-8.

57. Zheng R, Mao Y. Triglyceride and glucose (TyG) index as a predictor of incident hypertension: a 9year longitudinal population-based study. Lipids in Health and Disease. 2017;16.

58. Mai C, Hou M, Chen R, Duan D, Xu H, Lin X, et al. Cardiovascular risk factors in Chinese women with a history of gestational diabetes mellitus. Int J Clin Exp Med. 2015;8(11):21694-8.

59. Warren-Findlow J, Seymour RB, Huber LRB. The Association Between Self-Efficacy and Hypertension Self-Care Activities Among African American Adults \%J Journal of Community Health. 2012;37(1).

60. Pienyu R, Thomas S, Rajan SK. History of Gestational Diabetes Mellitus, Self-efficacy and Coping in Postpartum Women: A Pilot Study. Asian Women. 2018;34(4):101-15.

61. M ST, J BM, Justin TS, S TG, Jolaade K, F CS, et al. Association Between High Perceived Stress Over Time and Incident Hypertension in Black Adults: Findings From the Jackson Heart Study. \% J Journal of the American Heart Association. 2019;8(21).

62. McEwen BS, Gianaros PJ. Central role of the brain in stress and adaptation: Links to socioeconomic status, health, and disease \%J Annals of the New York Academy of Sciences. 2010;1186(1).

63. Gebreab SY, Diez-Roux AV, Hickson DA, Boykin S, Sims M, Sarpong DF, et al. The contribution of stress to the social patterning of clinical and subclinical CVD risk factors in African Americans: The Jackson Heart Study \%J Social Science \& Medicine. 2012;75(9). 
64. Davidson M, Boland EA, Grey M. Teaching teens to cope: coping skills training for adolescents with insulin-dependent diabetes mellitus. Journal of the Society of Pediatric Nurses : JSPN. 1997;2(2):6572.

65. Chai S, Yao B, Xu L, Wang D, Sun J, Yuan N, et al. The effect of diabetes self-management education on psychological status and blood glucose in newly diagnosed patients with diabetes type 2 . Patient Education and Counseling. 2018;101(8):1427-32. 